\title{
A Social Network Analysis on Venture Capital Alliance's Exit from an Emerging Market
}

\author{
Jing Wu $\mathbb{D}^{1}{ }^{1}$ Chuan Luo, ${ }^{2}$ and Ling Liu ${ }^{2}$ \\ ${ }^{1}$ School of Economic Information Engineering, Laboratory for Financial Intelligence and Financial Engineering, \\ Southwestern University of Finance and Economics, No. 555 Liutai Ave, Wenjiang, Chengdu 611130, China \\ ${ }^{2}$ School of Economic Information Engineering, \\ Collaborative Innovation Centre for the Innovation and Regulation of Internet-based Finance, \\ Southwestern University of Finance and Economics, No. 555 Liutai Ave, Wenjiang, Chengdu 611130, China
}

Correspondence should be addressed to Jing Wu; kaitlynwu@swufe.edu.cn

Received 14 May 2020; Accepted 11 June 2020; Published 28 June 2020

Guest Editor: Thiago Christiano Silva

Copyright (C) 2020 Jing Wu et al. This is an open access article distributed under the Creative Commons Attribution License, which permits unrestricted use, distribution, and reproduction in any medium, provided the original work is properly cited.

\begin{abstract}
This study investigated the impacts of network structure on a venture capital (VC) alliance's successful exit from an emerging market by empirically analyzing joint VC data in China. We find that, compared to a mature capital market, the mechanism not only has a certain commonality but also shows the emerging market's particularities. From the commonality perspective, the mechanism has a positive effect on successful exit by obtaining heterogeneity information. These particularities are manifested in the following three aspects. First, the mechanism is not conducive to deepening the enterprise value chain to establish credibility by obtaining short-term cash during an initial public offering with the enhancement of the VC alliance's intervention ability for enterprise development. In addition, a VC alliance's independent judgment is bound by the VC market. Furthermore, the problem of over-trust in investees reduces the likelihood of a VC alliance's successful exit. Therefore, we should pay more attention to the particularity of emerging markets such as China to improve the relevant management mechanism.
\end{abstract}

\section{Introduction}

The financial capital provided to startups and small business with perceived potential for long-term growth is widely known as venture capital (VC), which is an important source of funding for startups with low levels of access to financial support. Currently, the high-tech sector (e.g., integrated circuit, big data, artificial intelligence, and eHealth) received more support from VC. For instance, at the end of 2019, Qualcomm Ventures announced to invest up to $\$ 200$ million in startups helping build the $5 \mathrm{G}$ ecosystem, to help accelerate $5 \mathrm{G}$ innovation beyond the smartphone and drive $5 \mathrm{G}$ adoption (the information was accessed on 2020/03/01 at https://www.qualcommventures.com/5g-ecosystem-fund).

By supporting a wide range of high-tech startups, VC ultimately promotes both economic growth and industry innovation [1].
Because of the constraints of resources endowment and information cost, VC firms are generally restricted by the shortage of necessary information [2]. To this end, VC firms build strategic alliances through joint investments. Depending on the unique advantages of promoting complementary information resources and overcoming the constraints of information boundaries [3-5], VC firms' joint investment helps decrease the possibility of adverse selection when choosing investment project, provides specific support for investees, achieves effective control of the investment environment, and even improves exit performance [6-8]. Therefore, as one of the most important forms of VC, VC alliance has become the mainstream method of investment in the VC market. VC alliance not only helps improve the financial status and operating performance through synergy but also effectively alleviates the financial constraints for VC alliance partners [9]. 
The entire VC alliance's successful exit in the investees becomes the representative method of increasing a VC's competitive advantages and promoting the effective circulation of investment value chain because it not only reflects joint investment's performance but also helps guarantee the persistence of each VC firm's investment capacity. There are various ways for $\mathrm{VC}$ firms to exit the investment, including buy-back, merger and acquisition (M\&A), stock-right transfer, an initial public offering (IPO), management buyout, and reverse merger. Exit through IPO is generally considered successful because it is the most profitable for VC firms [10-12]. The growth of VC in the US market guarantees the availability of exit through IPO. However, if regulations are stricter (unlike in the US) or the financial market is underdeveloped, VC firms find it difficult to implement an IPO as an exit strategy [13]. Taking a firm public through an IPO would be more expensive, complex, and time-consuming in an emerging market that is underdeveloped (e.g., China, Vietnam, Thailand or Malaysia) than in a developed market (e.g., US, UK, Germany) [13]. Thus, understanding the mechanism of a VC alliance's exit through IPO in emerging markets is critical, whereas most studies investigate VC-related issues in the US market [14-16].

Extant studies have widely investigated the determinants of the VC's successful exit from both VC (including VC firm, entrepreneurial firm, VC fund, and VC market) and macroeconomic environmental perspectives [2, 17-21]. This study is different from previous researches in two ways. First, we primarily explore the impacts of the VC alliance's social network on its likelihood of successful exit. Given that highquality information resources are crucial for the formation of competitive advantages in each link of the value chain, a VC's information superiority contributes to its successful exit. Based on a joint investment network, a VC alliance can enhance its information search capacity through efficient network structure (i.e., interorganizational network). In addition, a VC alliance can rely on the information-sharing relationship between the VC alliance and its investees (i.e., intraorganizational network) to strengthen its capacity to understand information. Thus, both the interorganizational and intraorganizational network structure of a VC alliance are expected to significantly affect its likelihood of successful exit. Second, we study the potential factors that would affect the entire VC alliance's successful exit instead of the exit of a single VC firm. By empirically analyzing the effects of network structure on the likelihood of a VC alliance's exit through IPO using a sample of $496 \mathrm{VC}$ alliances formed by all 630 VC firms in China from 2000-2013, we observe that a VC alliance's interorganizational and intraorganizational network structure (i.e., information heterogeneity, network cohesion, network compactness, alliance size, and so on) significantly affect its likelihood of successful exit.

\section{Literature Review}

2.1. Value Chain of Venture Capital Investment. VC typically generates above-average returns while entailing high risk for VC investors [8, 17]. To achieve success in VC investment, we can further analyze the competitive advantages of $\mathrm{VC}$ firms based on the value chain analysis $[22,23]$. VC's value chain can be divided into four main links: identifying highquality entrepreneurs (entry), proposing valuable suggestions for investees (incubation), monitoring investees' behaviors (control), and successfully exiting the investment (exit). Of these links, exit is critical for the survival and growth of the VC industry [24]. First, it is only when the VC successfully exits that the value of the investment can be achieved and the VC firm's reputation on the market can improve $[12,25]$. Second, the likelihood of a successful and timely exit partially determines a VC firm's investment decisions because it allows the VC firm to effectively predict its returns [11]. Third, given that exit enables the recycling of VC backers' funds into new investments, a VC's successful exit enhances investors' willingness to provide capital for initial and follow-on funds [10]. Therefore, understanding how VC firms can successfully exit is critical for both academia and practitioners.

2.2. Successful Exit of Venture Capital. Prior studies find that exit through IPO is the most profitable way of exit for VC firms, followed by exit through M\&A [10-12]. Exit through IPO thus is typically considered as a successful VC exit way. Extant studies on VCs' successful exits [18-20] have widely investigated the determinants of the time and method of VC exit. As shown in Table 1, prior studies have primarily examined the impacts of the following four aspects of potential factors on a VC firm's successful exit (i.e., the likelihood of exit through IPO), including VC firm, entrepreneurial firm, VC fund, and VC market perspectives. In addition, researchers have empirically tested the impacts of country-level factors such as trade protection, legality, economic freedom, government size, price stability, cultural distance, economy size, and burden of taxation when investigating the successful exit of international joint ventures $[18,20,26]$.

The second research stream focuses on the impacts of a VC's successful exit on a firm's optimal strategies and performances. Among them, Schwienbacher [27] analyzes the influence of a VC firm's exit method on a startup's innovation strategy by developing an analytical model. He proves that the startup has incentives to distort the innovation strategy to induce the VC to take the firm public. Bascha and Walz [28] investigate the dynamics of exit methods and contract design in VC through an analytical approach. Their results indicate that, using convertible securities, the ex ante agreed optimal exit strategy can be achieved. Gerasymenko and Arthurs [29] empirically prove the positive effects of a VC firm's forecast of IPO exit on the breadth of its advice and the possibility of founder-CEO replacement.

Although these studies have adequately discussed the determinants and consequences of a VC's successful exit, little research has been done to investigate the potential factors that can significantly affect the successful exit of the entire VC alliance. By recognizing a joint VC's unique advantages in improving investment performance based on 
TABLE 1: The determinants of VC's successful exit.

\begin{tabular}{|c|c|c|}
\hline Perspective & Factors & References \\
\hline VC firm perspective & $\begin{array}{c}\text { Syndicate size (the scale of joint VC), age, round of investment, investment experience, } \\
\text { partnership }\end{array}$ & {$[17-20]$} \\
\hline $\begin{array}{l}\text { Entrepreneurial firm } \\
\text { perspective }\end{array}$ & $\begin{array}{c}\text { Industry, stage of development, stage of technological development, geographical location, } \\
\text { investment duration, total amount of investment }\end{array}$ & {$[17-20]$} \\
\hline VC fund perspective & Fund age, old fund, fund size & {$[18]$} \\
\hline VC market perspective & VC industry competition, IPO market conditions, market depth & {$[20]$} \\
\hline
\end{tabular}

the information superiority of strategic alliances [9], joint investments are widely adopted by VC firms in the current market. Given that network structures significantly affect the alliance formation and information superiority of joint VCs $[16,30], \mathrm{VC}$ alliances with different network structures are expected to have different possibilities of successful exit. Therefore, it is necessary to empirically examine the successful exit of a VC alliance from a social network perspective.

2.3. Social Network and Venture Capital's Successful Exit. VC alliance generates different collaboration and communication networks. Social network analysis thus adopts a curial approach to analyzing the characteristics of these networks. A few studies have investigated VC firms' successful exit from a social network perspective. Dai et al. [17] indicate that firms with both foreign and local VC partnership are more likely to successfully exit the investment. Jääskeläinen and Maula [31] examine the impacts of financial intermediaries' direct and indirect network ties on a VC's successful exit. Their results show that, as a critical dimension of distance in addition to its cultural and geographical dimensions, network distance (network ties) directly affects the likelihood of a VC firm's successful exit. Meschi and Wassmer [32] empirically examine the influence of structural embeddedness (including centrality and network density) on the successful exit of international joint ventures. Hochberg et al. [2] and Nie et al. [21] investigate the influence of network position (i.e., degree centrality, closeness, betweenness, and density) on the success of VC investment (which is operationalized as the exit through IPO). However, these studies have focused only on the impacts of structural embeddedness on a VC firm's successful exit. In addition, by utilizing the studies in a mature market (i.e., the US VC market), they found that a better network position (i.e., a higher level of network centrality) would positively contribute to the success of VC investment. To fill these research gaps and examining whether the network position still significantly affect VC success in an emerging market, we empirically investigate how both interorganizational and intraorganizational network structure affect a VC alliance's successful exit in the Chinese market.

\section{Research Hypotheses}

By summarizing previous literature on social network analysis (e.g., [17, 33-36]), we investigate the impacts of both interorganizational and intraorganizational network structure on the successful exit of VC alliances. Interorganizational network structure of a VC alliance describes the structure of all members' network positions, which directly measures the structure of ties among VC firms. On the contrary, by measuring the relationship between investors (i.e., VC firms) and investees, intraorganizational network structure captures the status of the ties between VC firms and investees. Thus, all the possible relationships among key actors (i.e., investors and investees) in the VC ecosystem are included in our analysis.

3.1. Interorganizational Network Structure. We investigate the impacts of interorganizational network structure from three aspects: information heterogeneity, network cohesion, and network compactness.

3.1.1. Information Heterogeneity. The superiority of information heterogeneity of the VC alliance can promote the investee's development. Specifically, it helps alliance members eliminate redundant partners and devote more efforts to managing complementary connections. The VC alliance thus can increase its information-search efficiency and capture more useful information, thereby not only encouraging investees to develop more competitive products and service but also monitoring investees' operations better. In addition, the superiority of information heterogeneity of the VC alliance could increase investees' market influences. It makes benefits for $\mathrm{VC}$ firms to obtain unique information from heterogeneous fields [37]. Thus, the VC alliance with the superiority of information heterogeneity can comprehensively identify its opportunities and challenges and provide better suggestions for the investee. Thus, the VC alliance's advantages in the area of heterogeneous information search promote the investee's development, thus increasing the VC alliance's likelihood of successful exit. Therefore, we hypothesize the following.

Hypothesis 1. (H1). A venture capital alliance is more likely to successfully exit when its capacity for controlling heterogeneous information increases.

3.1.2. Network Cohesion. Network cohesion reflects the closeness of the connection between an alliance member and other members. A higher level of network cohesion indicates a larger amount of social capital that can form trust and collaborative relationships [38]. The social capital that is increased can promote the consistency of internal members' 
behaviors, produce consistent behavioral expectations, and increase the efficiency of decisions and behaviors [39]. Thus, relying on close connections with other VC firms, a VC firm can increase its capacity for information search to guarantee its investee's healthy development and deliver that investee's value to the VC alliance. However, its investment opinion would be limited in a small scope and is likely to produce herd behaviors because of high network cohesion. During the early stage of the VC market, VC firms' overall capacities to reduce information asymmetry are weak and most VC firms are active in a small group because they usually invest in a few industries to form their expert fields because of the shortage of information resources. If the VC firm has more connections in the small group, its decision is more affected by the constraints of the group, and it is more likely to emulate others' behaviors. Thus, although increased social capital can improve a VC firm's capacity to acquire information, the firm also becomes much more reliant on other members, likely causing herd behaviors. We therefore hypothesize the following:

Hypothesis 2. (H2). When a VC alliance's network cohesion is increased, the alliance is more affected by the constraints of VC market information, and its likelihood of successful exit decreases.

3.1.3. Network Compactness. According to social network theory, network compactness [40] is related to the efficiency of problem solving, perception of leadership, and the personal satisfaction of participants. The VC alliance with a higher level of network compactness can promote the investee's development, monitor the investee's operations, and provide necessary support for the investee to increase market reorganization. In the context of an emerging market, a VC alliance's network compactness is more likely to negatively affect its successful exit because the alliance has the speculative motivation to increase its reputation by raising IPO-based short-term cash. This type of speculative motivation is not beneficial for increasing the depth of the enterprise's incubation. On one hand, a VC alliance pays more attention to short-term benefits. Most VC firms in the Chinese market are quite young and need to increase their self-reputation and competitive abilities through their investees' IPOs. To accelerate the IPO process, a VC alliance might not consider an enterprise's long-term development or enhance the depth of its incubation. When an alliance exhibits a higher level of network compactness, its industrial influence will increase. Thus, the higher compactness alliance has greater capacity to promote enterprises that engage in short-term-based strategies, thus negatively affecting the success of the investment. On the other hand, a VC alliance's support for an investee is more likely to decrease. The higher compactness network would continuously focus its resources on the investee that can raise short-term cash through an IPO because the member can observe more investment opportunities depending on its network superiority. Thus, when an investee's product value and market share cannot support an investor's need for IPO-based short-term cash, the alliance with higher compactness is more likely to exit through M\&A or stock right transfer. The investee's obtained support thus would decrease. Therefore, in the Chinese VC market, the higher compactness of the VC alliance is more likely to have a negative impact on its successful exit based on the investment incentive of establishing a short-term reputation. We thus hypothesize the following:

Hypothesis 3. (H3). The higher network compactness of the $\mathrm{VC}$ alliance is more likely to have a negative impact on its successful exit based on the investment incentive of establishing a short-term reputation.

3.2. Intraorganizational Network Structure. Intraorganizational network structure focuses on information sharing relationships among alliance members, which can reflect members' capacities for understanding information. We investigate the impacts of intraorganizational network structure from two aspects: ties to investee and alliance size.

3.2.1. Ties to Investee. Abundant ties to investees help VC firms share more personal and implicit knowledge, such as strategies and profit margins. Because implicit knowledge is tacit, viscous, and difficult to imitate [41], network members find it difficult to identify, copy, and merge, and it is difficult for a VC alliance to acquire such information based on network location. The increase in the number of ties to investees promotes the transformation of implicit knowledge, the formation of information-sharing customs, and even the collaborative solution of problems [42]. However, such an information-sharing relationship between a VC alliance and its investee that is too close can cause the overrelational embeddedness problem, decreasing the likelihood of the VC alliance's successful exit. According to the analysis of over-relational embeddedness $[43,44]$, trust is considered the foundation of the existence of relational embeddedness. A VC alliance's over-trust in its investee is considered to be the over-relational embeddedness problem. More specifically, if a VC alliance is too close to the investee, the alliance not only is more likely to over-believe in the investee's positive and optimal behaviors [43] but also finds it difficult to identify the firm's irrational investment behaviors and the "inside story" underlying a healthy transaction [44]. Therefore, the investee's development is negatively affected, and we hypothesize the following:

Hypothesis 4. (H4) A greater number of ties between a venture capital alliance and its investee negatively affects the alliance's successful exit.

3.2.2. Alliance Size. The size of the alliance significantly affects the scope and quality of the information that can be obtained by the VC alliance. The likelihood of successful exit thus is influenced by the size of the VC alliance [19]. According to the theory of "implicit contract," the VC alliance and the investee have greater capacities and incentives 
to promote the investee's IPO when the size of VC is increased [25]. Thus, we hypothesize the following:

Hypothesis 5. (H5) The alliance size positively affects the alliance's successful exit.

\section{Methodology}

4.1. Data. The data was collected from the Zero2IPO database, which provides academic data services for $\mathrm{VC} / \mathrm{PE}$ investment institutions, government, and investment banks. The data for all of the VCs from 2000-2013 in the Zero2IPO Database were collected as the initial sample, which contains 2365 VC firms and 7559 investees in 22 industries. After deleting the items with missing data (including investee data, partner data, or financing amount data), we obtain our final sample. There are $496 \mathrm{VC}$ alliances invested by $630 \mathrm{VC}$ firms. VC firms with higher levels of centrality are expected to have more market influence. Based on the analysis of network centrality, we find that each year's Top $50 \mathrm{VC}$ firms play dominant roles in the Chinese VC market. According to the statistics, the number of IPO enterprises supported by these Top 50 VC firms covers $61 \%$ of IPO enterprises.

4.2. Network Construction. A VC alliance's network is constructed based on its past cooperation relationships with other firms. We use a dummy 0-1 indicator to code the past cooperation relationship between two VC firms, which takes the value of 1 if these two $\mathrm{VC}$ firms have previously cooperated and the value of 0 if they have not. A matrix of 0 1 type that can reflect a VC firm's cooperation history is obtained after the coding; that matrix is considered the $\mathrm{VC}$ firm's social network. We establish each VC firm's network in a four-year window. For instance, the VC firm's interorganizational network structure in the year 2013 is calculated by its network connections from 2010-2013. Similarly, VC firms' intraorganizational network structure in 2012 is computed by its network relationships during 2009-2012.

4.3. Measurement. The unit of analysis in this study is VC alliance. We firstly ensure the concepts of the joint VC firm's network and VC alliance used in this study. Compared to the case in which the VC alliance begins the investment, the impacts of networked information superiority on a VC alliance's successful exit are more obvious and serious when the alliance exits the investment. Moreover, it is only when the VC alliance exits the investment that networked information superiority can comprehensively reflect the alliance's support intensity for the investee throughout the VC process. Therefore, the VC alliance refers to the set of all VC firms when the alliance exits the investment. For instance, a successfully exited VC alliance is the set of all VC firms that support the enterprise's IPO. In addition, the VC alliance's network is measured by the information-sharing relationship formed by all VC firms in the process of joint investment before the alliance's exit.
4.3.1. Dependent Variable. Given that an IPO is the most profitable way for a VC alliance to exit the investment [12], we denote the dependent variable, the VC alliance's successful exit (SE), as whether the alliance exits the investment through IPO, which takes the value of 1 if the alliance exits through an IPO and the value of 0 if the alliance does not exit through an IPO.

4.3.2. Independent Variables. We measure the interorganizational and intraorganizational network structure of VC alliances based on prior social network studies. With the superiority of information heterogeneity, there will be fewer redundant connections, and the marginal benefits of information will increase [37]. The structural hole measures the network members' capacities to acquire heterogeneous information and control other members' informative communications. Thus, the alliance member can use the advantages of the structural hole to increase its variety of perspectives and opinions, obtaining additional benefits through the cumulative and nonredundant network [45]. The Burt constraint index can effectively reflect an alliance member's lack of structural holes [45]. Researchers often use the differentiation between 1 and the Burt constraint index to measure the richness of structural holes [36], which can reflect the number of a VC firm's structural holes. The VC firm with a lower Burt constraint index exhibits more structural holes and a higher level of information heterogeneity superiority. Based on the former assumption, the $\mathrm{VC}$ firm $j$ 's Burt constraint index $\left(C_{j}\right)$ is given as

$$
C_{j}=\sum_{l=1}^{M} C_{j l}=\sum_{l=1}^{M}\left(P_{j l}-\sum_{q=1}^{M} P_{l q} \cdot P_{q l}\right)^{2}, \quad j \neq l \neq q,
$$

where $C_{j l}$ is a measure of the VC firm $j$ 's dependence on the $\mathrm{VC}$ firm $l$ and $P_{j l}$ represents the proportion of the VC firm $j$ 's network time and energy spent on the VC firm $l$. In particular, $P_{j l}=Z_{j l} / \sum_{q} Z_{j q}$ and variable $Z_{j l}$ measures the strength of connection between the $\mathrm{VC}$ firm $j$ and $l$. The calculations of $P_{l q}$ and $P_{q l}$ are the same as the computation of $P_{j l}$. We measure the VC alliance $i$ 's information heterogeneity as the maximum structural hole of the alliance members. Mathematically,

$$
\text { heterogeneity }_{i}=\max _{j=1,2, \ldots, M}\left\{1-C_{j}\right\} \text {. }
$$

VC alliance's network cohesion can reflect its connection with other network members, indicating the degree to which it can obtain support or constraint from the networked information resources. A member's network cohesion is measured by network density, which is computed as the ratio of its real connections with other members and all potential connections in the alliance. The maximum network density of the VC firm in the alliance is employed to represent the VC alliance's network cohesion. Suppose that the VC firm $j$ has $T_{j}$ connections with other members and there are $M \mathrm{VC}$ firms in the VC alliance $i$. Thus, the alliance's network cohesion is calculated as 


$$
\operatorname{cohesion}_{i}=\max _{j=1,2, \ldots, M}\left\{\frac{T_{j}}{[M(M-1)] / 2}\right\} .
$$

According to Freeman [34], network compactness is measured by the network centrality. In the network of VC alliance, a VC firm's centrality is represented by the number of other VC firms that are directly connected with it [9]. In this study, we define the VC alliance's network centrality as the maximum degree of centrality of the VC firms in the alliance. Suppose that the VC alliance $i$ is formed by $M \mathrm{VC}$ firms and that there are $N_{j}\left(N_{j} \leq M\right)$ VC firms connected with the VC firm $j$. Then, the VC firm $j$ 's network centrality is $N_{j}$ and the alliance $i$ 's network compactness is

$$
\text { compactness }_{i}=\max _{j=1,2, \ldots, M}\left\{N_{j}\right\} \text {. }
$$

Furthermore, prior studies (e.g., [46, 47]) have widely used the term "past cooperation relationship" among network members to measure the impact of relational embeddedness, thus providing theoretical foundations for this research. If the VC firm participates in additional rounds of financing, its implicit knowledge is deeply shared and its cooperation relationship with others will be enhanced. Thus, the total number of investment rounds in which the VC firm participates can better reflect its degree of information sharing with others. The VC alliance's ties to investee is measured by the maximum number of financing rounds in which the VC firm (in the alliance) participates. Suppose that the VC firm $j$ (in alliance $i$ ) has participated in $R_{j}$ rounds of joint investments. In that case, the $\mathrm{VC}$ alliance $i$ s ties to investee is given as

$$
\text { relationship } \max _{i}=\max _{j=1,2, \ldots, M}\left\{R_{j}\right\} \text {. }
$$

The alliance size $\left(\mathrm{Size}_{i}\right)$ is computed by the number of VC firms in the alliance.

4.3.3. Control Variables. Regardless of these network characteristics, there are other important factors that significantly affect how a VC alliance exits. Prior related studies $[48,49]$ have claimed that when an alliance member's investment experience (Experience ${ }_{i}$ ) increases, the VC alliance's personal information superiority also increases, thus promoting the alliance's successful exit. Sorensen [49] believes that the total number of rounds of investment better represents a VC firm's investment experience. We thus employ the VC firm's maximum total investment rounds in the alliance to measure the variable of the VC alliance's investment experience.

Moreover, the round of investment $\left(\right.$ Round $\left._{i}\right)$ is also highly correlated to the VC alliance's likelihood of successful exit [2]. The investee in the previous VC round is expected to be less mature. VC support is thus more important in the previous round. We choose the VC firm that has the most influence (i.e., the largest value of network centrality) in the alliance as the research subject. A dummy variable is introduced to indicate whether the VC firm with the largest centrality participates in the first-round investment, which takes the value of 1 if it is involved in the first-round financing and 0 otherwise.

Furthermore, the market depth (MarketDepth ${ }_{i}$ ) at the stage of the enterprise's IPO is composed of floating capital and the market space for IPO enterprises. This type of market depth also influences the investee's IPO process. We use the total number of successfully exited VCs during the year to measure the market depth during that year.

In addition, to avoid potential omitted variable bias, we include time fixed effects and industry fixed effects in the empirical model. In the $\mathrm{VC}$ market, the strategies and performances of $\mathrm{VC}$ alliances are related to the environmental factors that are specific to different years. Therefore, we include the year dummies $\left(\right.$ Year $_{t}$ ) in the model to account for the time fixed effects. Since different industries may have specific environmental characteristics, such as industry competition, centralization, and growth, we also include the industry dummies (Industry ${ }_{i}$ ) to control for the industry fixed effects.

4.4. Empirical Approach. Based on a Probit model, we conduct a regression analysis of the VC alliance's likelihood of choosing the IPO method of exit to analyze the impacts of network structure on the VC alliance's successful exit. The Probit model used in both the prediction and validation models is given as follows:

$$
\begin{aligned}
\operatorname{Pr}\left(\mathrm{SE}_{i}=1\right)= & \beta_{0}+\beta_{1} * \text { Heterogeneity }_{i}+\beta_{2} * \text { Cohesion }_{i} \\
& +\beta_{3} * \text { Compactness }_{i} \\
& +\beta_{4} * \text { Relationship }_{i}+\beta_{5} * \text { Size }_{i} \\
& +\beta_{6} * \text { Experience }_{i}+\beta_{7} * \text { Round }_{i} \\
& +\beta_{8} * \text { MarketDepth }_{i}+\beta_{9} * \text { Year }_{t} \\
& +\beta_{10} * \text { Industry }_{i}+\varepsilon_{i},
\end{aligned}
$$

in which $\mathrm{SE}_{i}$, Heterogeneity ${ }_{i}$, Cohesion $_{i}$, Compactness ${ }_{i}$, Relationship $_{i}$, Size $_{i}$, Experience ${ }_{i}$, Round $_{i}$, and MarketDepth refer to the VC alliance $i$ 's successful exit through IPO, capacity for controlling information heterogeneity, network cohesion, network compactness, ties to investees, alliance size, investment experience, the round of investment, and the market depth at the stage of the enterprise's IPO, respectively. Year $_{t}$ and Industry ${ }_{i}$ refer to the time and industry fixed effect. $\varepsilon_{i}$ denotes the error term.

\section{Results}

5.1. Descriptive Statistics and Correlation. The summary statistics and correlations of key variables are reported in Table 2. The results indicate significant differences among $\mathrm{VC}$ alliances in terms of their network structure and other characteristics. Academic researchers have widely acknowledged that multi-collinearity is serious only when correlations are higher than the critical value of $0.70[50,51]$. The correlations of key variables in this research are all lower than the threshold, thus indicating that serious multi-collinearity does not exist among independent variables. 
TABLE 2: Descriptive statistics and correlations of variables.

\begin{tabular}{|c|c|c|c|c|c|c|c|c|c|c|}
\hline Variable & Mean & Std. & 1 & 2 & 3 & 4 & 5 & 6 & 7 & 8 \\
\hline 1. $\mathrm{SE}_{i}$ & 0.82 & 0.38 & & & & & & & & \\
\hline 2. Size $_{i}$ & 1.15 & 1.70 & 0.07 & & & & & & & \\
\hline 3. Experience ${ }_{i}$ & 4.48 & 93.05 & 0.09 & 0.19 & & & & & & \\
\hline 4. MarketDepth & 5.21 & 81.74 & 0.23 & 0.03 & 0.24 & & & & & \\
\hline 5. Round $_{i}$ & 0.72 & 0.45 & 0.04 & -0.14 & -0.01 & -0.04 & & & & \\
\hline 6. Compactness ${ }_{i}$ & 3.53 & 24.73 & 0.02 & 0.27 & 0.69 & 0.16 & 0.01 & & & \\
\hline 7. Heterogeneity ${ }_{i}$ & -0.18 & 0.14 & 0.09 & 0.17 & 0.37 & 0.13 & -0.01 & 0.72 & & \\
\hline 8. Cohesion ${ }_{i}$ & -1.27 & 0.19 & -0.13 & 0.09 & -0.29 & -0.24 & 0.03 & -0.28 & -0.28 & \\
\hline 9. Relationship ${ }_{i}$ & 0.41 & 0.84 & -0.12 & 0.35 & 0.13 & -0.04 & -0.20 & 0.13 & 0.12 & 0.08 \\
\hline
\end{tabular}

5.2. Results of Prediction and Validation Models. The results of regression models on a VC alliance's successful exit are summarized in Table 3. Column 2 shows the regression results of the main estimation model. Columns 3 and 4 show the results of robustness tests which will be introduced in the next section.

5.2.1. Interorganizational Network Structure. The parameter estimate for the information heterogeneity is both significant and positive $(\beta=1.256, p<0.05)$, thus supporting $\mathrm{H} 1$ and indicating that the $\mathrm{VC}$ alliance is more likely to successfully exit if it holds more heterogeneous information resources. Furthermore, in support of $\mathrm{H} 2$, we find that network cohesion has a negative impact on the VC alliance's successful exit $(\beta=-0.263, p<0.10)$, indicating that the VC firm would be more constrained if it has more connections with other firms in a small investment group. Consistent with $\mathrm{H} 3$, a VC alliance's network compactness negatively affects its likelihood of successful exit $(\beta=-0.679, p<0.01)$, indicating that, under the incentive of short-term cash through an IPO to increase market reputation, if the VC alliance has a higher capacity to influence its investee's behaviors, the incubation depth for the investee would be decreased, ultimately decreasing the likelihood of the VC alliance's successful exit.

5.2.2. Intraorganizational Network Structure. The results also indicate that the ties between the VC alliance and the investee (ties to investees) is negatively correlated with the alliance's successful exit $(\beta=-0.345, p<0.10)$, thus supporting H4. The intuition for the obvious negative impact is that the VC alliance cannot effectively control over-trust problems caused by a deep information-sharing relationship. Furthermore, a VC alliance's capacities to acquire implicit knowledge through an information-sharing relationship might be too weak. Usually, the enterprises supported by VC are highly innovative, and the process of technology innovation is a long, complex journey. These increase a VC alliance's difficulty in identifying high-quality projects. In addition, the VC alliance's internal informationsharing mechanism might not be perfect. VC firms thus find it difficult to transfer high-quality information and make full use of implicit knowledge that they have obtained. Therefore, the VC alliance could increase the effectiveness of information usage by enhancing internal group learning and sharing more complementary information. The results also
TABLE 3: The results of regression analysis and robustness tests.

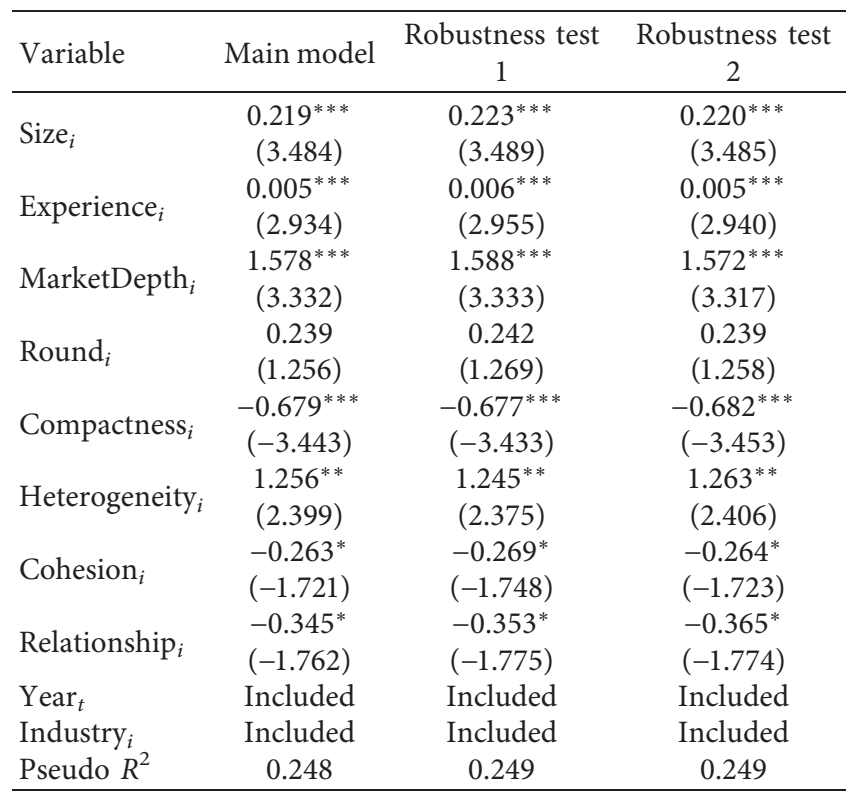

Notes: $N=496$; coefficients are shown and robust t-values are in parentheses; significance level: ${ }^{* * *} p<0.01 ;{ }^{* *} p<0.05 ;{ }^{*} p<0.10$.

demonstrate that the alliance size significantly and positively affects the VC alliance's likelihood of successful exit $(\beta=0.219, p<0.01)$, in which H5 is supported.

5.2.3. Control Variables. The results demonstrate that the VC alliance's investment experience and market depth all significantly and positively affect the VC alliance's likelihood of successful exit. However, the round of the largest-centrality VC firm that joins the alliance does not significantly affect the VC alliance's likelihood of successful exit. The intuition is that a serious information-asymmetry problem widely exists at all stages of an enterprise's development. The VC alliance therefore should not ignore information asymmetry problems in any development stage.

5.2.4. Fixed Effects. To avoid potential endogeneity bias, we consider the fixed effects of time and industry on a VC alliance's successful exit (due to space limit, the fixed effects of time and industry are provided upon request.). Generally, a VC alliance is more likely to exit through IPO in the 20052006 bull market, but the difficulty of a VC alliance's 
successful exit has increased in the current bear market, especially in 2010-2011. Thus, a VC alliance should seize the opportunities during the rising period of a capital market to promote its successful exit. When a VC alliance refers to the fixed effects of industry, it is more likely to successfully exit in the following two types of industries: emerging markets such as financial services and clean energy technologies and industries with mature technological standards such as chains and retail, automobile manufacturing, and machine manufacturing.

5.3. Robustness Checks. In addition, to ensure effective and stable results, we develop the validation model by conducting the robustness test based on two aspects. First, the VC firm's network structures are distinct in different time windows. We establish the four-year window network structure in the main model. Therefore, we conduct the robustness test by using the five-year window of the VC firm's network structures. The results are shown in "Robustness Test 1" (column 3) of Table 3. Second, we compute the mean of the alliance members' network structure to measure the VC alliance's network structure. For instance, a VC alliance's compactness is calculated based on the average of all of its members' degree centrality. The results are summarized in "Robustness Test 2" (column 4) of Table 3. When referring to the results of the robustness checks as shown in Table 3, we find that the results in a five-year window (in Robustness Test 1) are consistent with the results in the four-year window (in main model). In addition, as shown in the results of Robustness Test 2 , the results are also similar to the main model. Therefore, we conclude that our results are both effective and stable.

\section{Conclusion and Discussions}

In this paper, we have empirically analyzed the impacts of network structure on a VC alliance's successful exit (i.e., exit through IPO) at the initial stage of VC development. By empirically testing these hypothesized relationships through joint VC data in China for 2000-2013, we find that a VC alliance's network compactness, network cohesion, and ties to investee negatively affect its successful exit. In addition, the capacity of controlling information heterogeneity has a positive impact on its successful exit. These results indicate that, in addition to the fact that VC alliance can exert a positive effect on successful exit by obtaining heterogeneity information, there are some particularities manifested in the following aspects. First, it is not conducive to deepening the enterprise value chain to establish credibility by obtaining short-term cash during an IPO with the enhancement of a VC alliance's ability to intervene in the development of enterprises. Second, a VC alliance's independent judgment is bound by the VC market. Third, the problem of over-trust in investees reduces the likelihood of a VC alliance's successful exit. Therefore, we should pay more attention to the particularity of emerging markets such as China to improve VC performance. VC firms, entrepreneurial firms, and social planners are all guided by our results to implement better strategies and policies to promote $\mathrm{VC}$ development in an emerging market.

This study makes several theoretical contributions to the literature. First, we investigate a VC's successful exit from the social network perspective. Compared to previous studies that largely explore the determinants of a VC's successful exit from both the VC (including VC firm, entrepreneurial firm, VC fund, and VC market) and the macroeconomic environment perspectives [17-20], we have empirically investigated the impacts of a VC alliance's network structure on its successful exit from the social network perspective. In addition, unlike most prior studies of a single VC firm's successful exit, we explore the determinants of a VC alliance's successful exit. Given that VC alliance is beneficial for improving investment performance based on the information superiority of strategic alliances [9], joint investments are widely adopted by VC firms in the current market. Therefore, understanding the successful exit of the entire VC alliance is valuable in the context of collaborative culture. Furthermore, this research provides a more holistic understanding of a VC alliance's successful exit from the social network perspective. By investigating the influences of both interorganizational and intraorganizational networks (i.e., information heterogeneity, network cohesion, network compactness, ties to investee, and alliance size) on a VC alliance's successful exit, we contribute to related studies that only examined the impacts of VC's centrality and network density on its successful exit $[17,31,32]$.

This research also has several practical implications for VC firms, entrepreneurial firms, and social planners. First, VC firms should join the VC alliance with more heterogeneous information and not select an alliance that exhibits a high level of reliance on a single VC firm. In the process of VC alliance operation, alliance members should make full use of each member's advantages, enhance their collaborative efficiency, and cultivate investees' long-term value. Meanwhile, to alleviate the over-trust problem, alliance members should further perfect the mechanism of stock option incentives and improve the principal-agent problem between investees and the VC alliance. Second, entrepreneurial firms should not only actively communicate with the VC firm with higher impact in the alliance but also strategically use the information structure of VC firm-investeesmarket to promote market recognition of its value. Third, from the social planner perspective, given that VC firms generally lack information on $\mathrm{R} \& \mathrm{D}$ capacities and the VC market system is imperfect, the VC market is quite sensitive to government policy. Government thus can guide the VC market's value orientation by supporting leading VC firms to strengthen VC's support for emerging industries.

Although this work provides a more comprehensive understanding of VC alliances' successful exit from the social network perspective, it also has several limitations. First, we have focused on the influences of network structure at the alliance level. Whether the network attributes of various roles (such as leaders, followers, and herd leaders) in the VC alliance have different impacts on a VC alliance's successful exit is not examined. Future research should 
investigate various alliance members' network value and its impact on a VC alliance's successful exit. Second, we hypothesized and tested the linear relationship between network structure and a VC alliance's successful exit. However, these relationships might be U-shaped [52] or inverted U-shaped $[53,54]$. Therefore, we should further discuss the shapes of these relationships in future research. Third, we only considered the effects of network structure on a VC alliance's likelihood of exit through IPO. How these network structures affect a VC alliance's choice of other exit methods such as M\&A should be investigated in the future.

\section{Data Availability}

The data used to support the findings of this study are available from the corresponding author upon request.

\section{Conflicts of Interest}

The authors declare that they have no conflicts of interest.

\section{Acknowledgments}

This research was supported by MOE (Ministry of Education in China) Project of Humanities and Social Sciences (Project no. 20YJA630071) and the Fundamental Research Funds for the Central Universities (Project no. JBK2002025). The authors would like to thank Dr. He Li and Dr. Jian Zhang for the technical discussion of this research.

\section{References}

[1] S. Terjesen, P. C. Patel, J. O. Fiet, and R. D'Souza, "Normative rationality in venture capital financing," Technovation, vol. 33, no. 8-9, pp. 255-264, 2013.

[2] Y. V. Hochberg, A. Ljungqvist, and Y. Lu, "Whom you know matters: venture capital networks and investment performance," The Journal of Finance, vol. 62, no. 1, pp. 251-301, 2007.

[3] J. A. C. Baum, T. Calabrese, and B. S. Silverman, "Don't go it alone: alliance network composition and startups' performance in Canadian biotechnology," Strategic Management Journal, vol. 21, no. 3, pp. 267-294, 2000.

[4] J. A. C. Baum and R. Cowan, "Network-independent partner selection and the evolution of innovation networks," Management Science, vol. 56, no. 11, pp. 2094-2110, 2010.

[5] W. D. Jonard, "Syndicated investments by venture capital firms: a networking perspective," Journal of Business Venturing, vol. 2, no. 2, pp. 139-154, 1987.

[6] G. Ahuja, "Collaboration networks, structural holes, and innovation: a longitudinal study," Administrative Science Quarterly, vol. 45, no. 3, pp. 425-455, 2000.

[7] D. R. Gnyawali and R. Madhavan, "Cooperative networks and competitive dynamics: a structural embeddedness perspective," The Academy of Management Review, vol. 26, no. 3, pp. 431-445, 2001.

[8] P. Gompers, A. Kovner, and J. Lerner, "Specialization and success: evidence from venture capital," Journal of Economics \& Management Strategy, vol. 18, no. 3, pp. 817-844, 2009.

[9] J. Chen, T.-H. D. King, and M.-M. Wen, "Do joint ventures and strategic alliances create value for bondholders?" Journal of Banking \& Finance, vol. 58, no. 58, pp. 247-267, 2015.
[10] B. S. Black and R. J. Gilson, "Venture capital and the structure of capital markets: banks versus stock markets," Journal of Financial Economics, vol. 47, no. 3, pp. 243-277, 1998.

[11] D. Cumming, "Contracts and exits in venture capital finance," Review of Financial Studies, vol. 21, no. 5, pp. 1947-1982, 2008.

[12] P. A. Gompers, "Grandstanding in the venture capital industry," Journal of Financial Economics, vol. 42, no. 1, pp. 133-156, 1996.

[13] K. R. Song, I. Kim, and Y. K. Chang, "A reverse takeover as an exit strategy of venture capital: Korean evidence," PacificBasin Finance Journal, vol. 29, no. 29, pp. 182-198, 2014.

[14] B. L. Hallen, R. Katila, and J. D. Rosenberger, "How do social defenses work? A resource-dependence lens on technology ventures, venture capital investors, and corporate relationships," Academy of Management Journal, vol. 57, no. 4, pp. 1078-1101, 2014.

[15] Y.-R. Li and Y. Chen, "Opportunity, embeddedness, endogenous resources, and performance of technology ventures in Taiwan's incubation centers," Technovation, vol. 29, no. 1, pp. 35-44, 2009.

[16] U. Ozmel, J. J. Reuer, and R. Gulati, "Signals across multiple networks: how venture capital and alliance networks affect interorganizational collaboration," Academy of Management Journal, vol. 56, no. 3, pp. 852-866, 2013.

[17] N. Dai, H. Jo, and S. Kassicieh, "Cross-border venture capital investments in Asia: selection and exit performance," Journal of Business Venturing, vol. 27, no. 6, pp. 666-684, 2012.

[18] S. Espenlaub, A. Khurshed, and A. Mohamed, "Venture capital exits in domestic and cross-border investments," Journal of Banking \& Finance, vol. 53, no. 53, pp. 215-232, 2015.

[19] P. Giot and A. Schwienbacher, "IPOs, trade sales and liquidations: modelling venture capital exits using survival analysis," Journal of Banking \& Finance, vol. 31, no. 3, pp. 679-702, 2007.

[20] L. Wang and S. Wang, "Economic freedom and cross-border venture capital performance," Journal of Empirical Finance, vol. 19, no. 1, pp. 26-50, 2012.

[21] F. Nie, J. Zhang, and J. Wu, "Impact of network embeddedness on venture capital union's successful exit: mechanism and evidence," R\&D Management, vol. 28, no. 5, pp. 12-22, 2016.

[22] A.-F. M. El-Sayed, M. W. Dickson, and G. O. El-Naggar, "Value chain analysis of the aquaculture feed sector in Egypt," Aquaculture, vol. 437, no. 1, pp. 92-101, 2015.

[23] R. Lema, R. Quadros, and H. Schmitz, "Reorganising global value chains and building innovation capabilities in Brazil and India," Research Policy, vol. 44, no. 7, pp. 1376-1386, 2015.

[24] P. Gompers and J. Lerner, "The venture capital revolution," Journal of Economic Perspectives, vol. 15, no. 2, pp. 145-168, 2001.

[25] R. Nahata, "Venture capital reputation and investment performance々," Journal of Financial Economics, vol. 90, no. 2, pp. 127-151, 2008.

[26] D. Cumming, G. Fleming, and A. Schwienbacher, "Legality and venture capital exits," Journal of Corporate Finance, vol. 12, no. 2, pp. 214-245, 2006.

[27] A. Schwienbacher, "Innovation and venture capital exits*," The Economic Journal, vol. 118, no. 533, pp. 1888-1916, 2008.

[28] A. Bascha and U. Walz, "Convertible securities and optimal exit decisions in venture capital finance," Journal of Corporate Finance, vol. 7, no. 3, pp. 285-306, 2001.

[29] V. Gerasymenko and J. D. Arthurs, "New insights into venture capitalists' activity: IPO and time-to-exit forecast as 
antecedents of their post-investment involvement," Journal of Business Venturing, vol. 29, no. 3, pp. 405-420, 2014.

[30] F. Polidoro, G. Ahuja, and W. Mitchell, "When the social structure overshadows competitive incentives: the effects of network embeddedness on joint venture dissolution," Academy of Management Journal, vol. 54, no. 2, pp. 203-223, 2011.

[31] M. Jääskeläinen and M. Maula, "Do networks of financial intermediaries help reduce local bias? Evidence from crossborder venture capital exits," Journal of Business Venturing, vol. 29, no. 5, pp. 704-721, 2014.

[32] P.-X. Meschi and U. Wassmer, "The effect of foreign partner network embeddedness on international joint venture failure: evidence from European firms' investments in emerging economies," International Business Review, vol. 22, no. 4, pp. 713-724, 2013.

[33] A. Al-Laham and V. Souitaris, "Network embeddedness and new-venture internationalization: analyzing international linkages in the German biotech industry," Journal of Business Venturing, vol. 23, no. 5, pp. 567-586, 2008.

[34] L. C. Freeman, "Centrality in social networks conceptual clarification," Social Networks, vol. 1, no. 3, pp. 215-239, 1979.

[35] R. Gulati, N. Nohria, and A. Zaheer, "Strategic networks," Strategic Management Journal, vol. 21, no. 3, pp. 203-215, 2000.

[36] A. Zaheer and G. G. Bell, "Benefiting from network position: firm capabilities, structural holes, and performance," Strategic Management Journal, vol. 26, no. 9, pp. 809-825, 2005.

[37] M. Tortoriello, "The social underpinnings of absorptive capacity: the moderating effects of structural holes on innovation generation based on external knowledge," Strategic Management Journal, vol. 36, no. 4, pp. 586-597, 2015.

[38] S. C. James, "Social capital in the creation of human capital," American Journal of Sociology, vol. 94, no. 6, pp. 95-120, 1988.

[39] S. Gupta, A. Woodside, C. Dubelaar, and D. Bradmore, "Diffusing knowledge-based core competencies for leveraging innovation strategies: modelling outsourcing to knowledge process organizations (KPOs) in pharmaceutical networks," Industrial Marketing Management, vol. 38, no. 2, pp. 219-227, 2009.

[40] J. Scott, Social Networks: Critical Concepts in Sociology, Routledge, London, UK, 2002.

[41] J. S. Brown and P. Duguid, "Organizational learning and communities-of-practice: toward a unified view of working, learning, and innovation," Organization Science, vol. 2, no. 1, pp. 40-57, 1991.

[42] B. Uzzi, "Social structure and competition in interfirm networks: the paradox of embeddedness," Administrative Science Quarterly, vol. 42, no. 1, pp. 35-67, 1997.

[43] D. Jim and B. Frances, "Storm clouds and silver linings: responding to disruptive innovations through cognitive resilience," Entrepreneurship Theory and Practice, vol. 34, no. 1, pp. 197-216, 2009.

[44] F. Markus, F. Sharon, E. Matusik, and K. Mosa, "Do v.s. matter? The importance of owers on performance variance in start-up firms," Strategic Management Journal, vol. 30, no. 4, pp. 387-404, 2009.

[45] R. S. Burt, Brokerage \& Clusters, Oxford University Press, Oxford, UK, 2005.

[46] C. Cruz, R. Justo, and J. O. De Castro, "Does family employment enhance MSEs performance?” Journal of Business Venturing, vol. 27, no. 1, pp. 62-76, 2012.
[47] D.-Y. Kim, "Understanding supplier structural embeddedness: a social network perspective," Journal of Operations Management, vol. 32, no. 5, pp. 219-231, 2014.

[48] S. N. Kaplan and A. Schoar, "Private equity performance: returns, persistence, and capital flows," The Journal of Finance, vol. 60, no. 4, pp. 1791-1823, 2005.

[49] M. Sørensen, "How smart is smart money? A two-sided matching model of venture capital," The Journal of Finance, vol. 62, no. 6, pp. 2725-2762, 2007.

[50] W. Greene, Econometric Analysis, Prentice-Hall, Upper Saddle River, NJ, USA, 2003.

[51] J. Wooldridge, Introductory Econometrics: A Modern Approach, South-Western College Publication, Cincinnati, $\mathrm{OH}$, USA, 2003.

[52] J. E. Perry-Smith and C. E. Shalley, "The social side of creativity: a static and dynamic social network perspective," The Academy of Management Review, vol. 28, no. 1, pp. 89-106, 2003.

[53] G. Cattani and S. Ferriani, "A core/periphery perspective on individual creative performance: social networks and cinematic achievements in the hollywood film industry," Organization Science, vol. 19, no. 6, pp. 824-844, 2008.

[54] S. Paruchuri, "Intraorganizational networks, interorganizational networks, and the impact of central inventors: a longitudinal study of pharmaceutical firms," Organization Science, vol. 21, no. 1, pp. 63-80, 2010. 